\title{
FORMULASI TABLET PARACETAMOL SECARA KEMPA LANGSUNG DENGAN MENGGUNAKAN VARIASI KONSENTRASI AMILUM UBI JALAR (Ipomea batatas Lamk.) SEBAGAI PENGHANCUR
}

\author{
Nur Ani \\ Akademi Farmasi Tadulako Farma Palu \\ Email : any cute89@yahoo.co.id
}

\begin{abstract}
It has been conducted a research about paracetamol tablet formula with kempa technique directly using various concentration of parsnip creeps amylum (Ipomea batatas Lamk.) as dissolver. The result observation shows that all tablet qualifies to test tablet physical character of that. Cover wight uniformity, size uniformity, crispness, and violence, flohat are indicated accord with in Indonesian Pharmacopoeia. Based on analysis of variance quiz $f$ that there is no significant formula among uniformity, size uniformity, crispness and violence. All formula qualifies to test at dissolution.
\end{abstract}

Keywords : Amilum is parsnip creeps, destroyer material, tablet.

\section{PENDAHULUAN}

Kecenderungan penggunaan bahan obat alam atau herbal di dunia semakin meningkat. Selain ekonomis sumber tanaman obat di Indonesia sangat melimpah dengan jenis beraneka ragam. Tanaman berkhasiat obat menjadi sesuatu yang sangat potensial untuk dikembangkan budidayanya, proses penyarian bahan berkhasiatnya, dan teknologi untuk menjadikannya suatu sediaan farmasi. Salah satunya adalah bentuk sediaan tablet.

Tablet adalah sediaan padat yang mengandung bahan obat dengan atau tanpa bahan pengisi. teknologi pembuatan tablet diperlukan bahan tambahan yaitu bahan penghancur (disintegrant), pengisi (diluents), pengikat (binder) dan lubrikan.diantara bahan-bahan tersebut bahan penghancur merupakan salah satu bahan yang dibutuhkan dalam proses pembuatan tablet yang berfungsi untuk memudahkan pecahnya atau hancurnya tablet ketika masuk medium berair atau ketika kontak dengan cairan saluran pencernaan dan diharapkan tablet segera melepaskan kandungan zat aktif, oleh sebab itu zat penghancur merupakan 
Formulasi tablet paracetamol secara kempa langsung dengan menggunakan variasi konsentrasi amilum ubi jalar (Ipomea batatas Lamk.) sebagai penghancur

salah satu bahan tambahan yang menentukan efektifitasnya suatu sediaan tablet. ${ }^{1}$

Zat aktif yang digunakan untuk diformulasikan sebagai bentuk sediaan tablet adalah paracetamol. Parasetamol adalah salah satu obat golongan analgetik dan antipiretik. Pemilihan zat aktif (paracetamol) sebagai model bentuk sediaan padat karena obat ini banyak diminati oleh masyarakat, selain harganya murah, paracetamol juga mampu mengurangi atau menghilangkan demam tanpa mempengaruhi SSP (Susunan Saraf Pusat) atau menurunkan kesadaran dan juga tidak menimbulkan ketagihan.

Penelitian ini menggunakan bahan penghancur amilum ubi jalar, sebab ubi jalar lebih mudah didapat dan harganya pun relatif murah. Bahan penghancur berperan menjaga adanya system pori-pori dalam tablet pada saat tablet dikempa. Pori-pori ini mengakibatkan penetrasi air yang cepat saat tablet bersentuhan dengan air, sehingga tablet segera hancur.

Permasalahan pada penelitian ini adalah Apakah amilum ubi jalar sebagai bahan tambahan yang berfungsi sebagai zat penghancur dapat membentuk tablet kompresi yaitu tablet parasetamol dan apakah ada perbedaan yang signifikan pada amilum ubi jalar sebagai penghancur dengan konsentrasi $5 \%, 10 \%$ dan 15 $\%$.

Penelitian ini bermaksud untuk mengetahui perbedaan yang signifikan antara konsentrasi amilum ubi jalar sebagai penghancur dalam menghasilkan tablet paracetamol dan tujuannya adalah untuk menentukan konsentrasi bahan penghancur yang paling efektif.

Data hasil penelitian diolah dengan membandingkan hasil yang diperoleh dengan persyaratan yang tercantum dalam Farmakope Indonesia dan pustaka lainnya dan uji statistik menggunakan uji ansira (uji F). Uji ini untuk melihat perbedaan yang signifikan, dengan membandingkan harga $F$ hitung terhadap $\mathrm{F}$ tabel. Jika terdapat perbedaan yang signifikan antar perlakuan maka dilakukan uji lanjut sesuai nilai koefisien keragaman data yang diperoleh.

Penelitian ini diharapkan dapat memberikan informasi dalam bidang industri farmasi terutama mengenai teknologi formulasi dalam menentukan bahan penghancur yang baik dan murah dalam pembuatan tablet, sehingga diperoleh sediaan farmasi 
Formulasi tablet paracetamol secara kempa langsung dengan menggunakan variasi konsentrasi amilum ubi jalar (Ipomea batatas Lamk.) sebagai penghancur

yang berkualitas dengan harga yang terjangkau oleh konsumen.

\section{METODE PENELITIAN}

Bahan yang digunakan adalah paracetamol, avicel $\mathrm{PH} 102$, amilum ubi jalar, laktosa, talk. Penyiapan formulasi tablet paracetamol dimodifikasi dari formula standar paracetamol sebagai tablet ${ }^{2}$ :

Acetaminofen $300 \mathrm{mg}$

Polivinilpirolidon $22,5 \mathrm{mg}$

Laktosa $61,75 \mathrm{mg}$

Alkohol $14,5 \mathrm{ml}$

Asam stearat $9 \mathrm{mg}$

Talk $13,5 \mathrm{mg}$

Starch jagung 43,25 mg

Tabel 1. Formula tablet paracetamol secara kempa langsung dengan menggunakan variasi konsentrasi amilum ubi jalar sebagai penghancur.

\begin{tabular}{|c|c|c|c|c|}
\hline \multirow[b]{2}{*}{ Bahan } & \multirow[b]{2}{*}{ Fungsi } & \multicolumn{3}{|c|}{ Formula } \\
\hline & & $\begin{array}{c}\mathrm{I} \\
(\mathrm{mg})\end{array}$ & $\begin{array}{c}\text { II } \\
(\mathrm{mg})\end{array}$ & $\begin{array}{c}\text { III } \\
(\mathrm{mg})\end{array}$ \\
\hline $\begin{array}{l}\text { Paracetamol } \\
\text { (mg) }\end{array}$ & Bahan aktif & 180 & 180 & 180 \\
\hline Laktosa (mg) & Pengisi & 240 & 210 & 180 \\
\hline $\begin{array}{c}\text { Avicel PH } \\
102\end{array}$ & Pengikat & 120 & 120 & 120 \\
\hline $\begin{array}{l}\text { Amilum ubi } \\
\text { jalar (mg) }\end{array}$ & Penghancur & 30 & 60 & 90 \\
\hline Talk & $\begin{array}{l}\text { Glidan dan } \\
\text { lubrikan }\end{array}$ & 30 & 30 & 30 \\
\hline
\end{tabular}

Keterangan :

Formula I : Formulasi tablet oral paracetamol dengan kombinasi bahan penghancur amylum ubi jalar $5 \%$

Formula II : Formulasi tablet oral paracetamol dengan kombinasi bahan penghancur amylum ubi jalar $10 \%$

Formula III : Formulasi tablet oral paracetamol dengan kombinasi bahan penghancur amylum ubi jalar $15 \%$

\section{Prosedur kerja}

\section{Penimbangan bahan}

Menimbang parasetamol 180 mg, avicel PH 102, amilum ubi jalar, talk, dan laktosa dengan jumlah yang telah diperhitungkan.

\section{Pencampuran}

Mencampurkan bahan aktif paracetamol dengan bahan pengisi laktosa hingga homogen, selanjutnya menambahkan talk, amilum ubi jalar, dan avicel kemudian digerus hingga homogen.

\section{Kompresi tablet}

Campuran bahan untuk masingmasing formula 1, II, III, ditabletasi dengan metode cetak langsung menggunakan mesin tablet single punch hingga berbentuk hingga terbentuk tablet oral dengan bobot rata-rata $600 \mathrm{mg}$ per tablet. Selanjutnya tablet oral tersebut diuji mutu fisiknya.

\section{Pengujian Sifat Fisik Tablet \\ Keseragaman bobot tablet}

Sejumlah 10 tablet ditimbang, kemudian dihitung bobot rata-ratanya, untuk tablet yang bobotnya lebih dari 300 mg, jika ditimbang satu persatu maka tidak satu tablet pun yang bobotnya menyimpang lebih besar dari bobot rata-rata sebesar 5\% dan tidak satu tablet pun yang bobotnya 
Formulasi tablet paracetamol secara kempa langsung dengan menggunakan variasi konsentrasi amilum ubi jalar (Ipomea batatas Lamk.) sebagai penghancur

menyimpan lebih besar dari bobot rata-rata sebesar $10 \%$.

\section{Keseragaman ukuran}

Meletakkan 10 tablet, kemudian ketebalan luar tablet diukur memakai jangka sorong yang melengkung. Kecuali dinyatakan lain, diameter tablet tidak lebih dari $1^{1} / 3$ tebal tablet. Variasi ketebalan yang baik kurang lebih $5 \%$ dari nilai rata-ratanya, atau perbedaan ketebalan tablet harus tidak dapat dibedakan hanya dengan melihat tanpa mengukur.

\section{Kekerasan tablet}

Sejumlah 10 tablet diletakkan dengan posisi tegak lurus pada alat Hardness tester, tekanan ditingkatkan hingga tablet pecah dan hancur. Tekanan dibaca pada skala yang tertera pada alat tersebut yang dinyatakan dalam satuan $\mathrm{Kg}$.

\section{Kerapuhan tablet}

Sejumlah 10 tablet dibebas debukan, kemudian ditimbang dan dijatuhkan dari ketinggian \pm 1 meter. Tablet dibebas debukan lagi dan ditimbang kembali.

Kerapuhan tablet dihitung dengan rumus :

$\%$ kerapuhan $=\frac{M 1-M 2}{M 1} \times 100 \%$

Keterangan :

$\mathrm{M}_{1}=$ Bobot tablet sebelum uji

$\mathrm{M}_{2}=$ Bobot tablet sesudah uji

\section{Uji Disolusi Tablet}

\section{Menggunakan alat disolusi tipe 2}

Sebuah tablet dimasukkan ke dalam labu yang berisi media disolusi $900 \mathrm{ml}$ (seperti yang dinyatakan dalam monografi) yang mana terlebih dahulu alat disolusi yang berbentuk dayung terlebih dahulu dimasukkan ke dalam labu yang berisi media disolusi. Labu ini berbentuk silindris, suhu labu dipertahankan pada $37^{\circ} \mathrm{C} \pm 0,5^{\circ} \mathrm{C}$, dengan penangas bersuhu tetap. Motor diatur pada kecepatan yang ditentukan, kemudian cairan sampel diambil pada selang waktu tertentu untuk menentukan jumlah obat di dalam cairan tersebut.

\section{Disolusi tablet paracetamol}

Media disolusi : $900 \mathrm{ml}$ air, alat tipe 2 dengan kecepatan rotasi 50 rpm. Toleransi, dalam waktu 30 menit harus larut tidak kurang dari $80 \%(Q)$ $\mathrm{C}_{8} \mathrm{H}_{9} \mathrm{NO}_{2}$, dari jumlah yang tertera pada etiket. Penentuan kadar zat terlarut dilakukan dengan menggunakan spektrofotometer UV pada Spanjang gelombang $243 \mathrm{~nm}$.

\section{Analisa Hasil}

Data yang diperoleh dianalisis melalui dua pendekatan yaitu secara teoritis dan statistik. secara teoritis, hasil yang diperoleh dibandingkan dengan persyaratan yang tertera pada 
Formulasi tablet paracetamol secara kempa langsung dengan menggunakan variasi konsentrasi amilum ubi jalar (Ipomea batatas Lamk.) sebagai penghancur

Farmakope Indonesia dan pustaka lainnya.

Secara pendekatan statistik, hasil data yang diperoleh dari uji stabilitas fisik suspensi selanjutnya dianalisis dengan uji Ansira (Uji F) dengan taraf kepercayaan 95\% dan 99\%. Uji ini digunakan untuk mengetahui apakah antar formula terdapat perbedaan yang signifikan, dengan membandingkan harga $F$ hitung terhadap $F$ tabel. Jika $F$ hitung lebih kecil dari $\mathrm{F}$ tabel berarti tidak ada perbedaan yang signifikan, sebaliknya jika $\mathrm{F}$ hitung lebih besar dari $\mathrm{F}$ tabel berarti ada perbedaan yang signifikan antar formula.
Selanjutnya untuk mengetahui formula mana yang berbeda maka dilakukan uji lanjut, berdasarkan nilai koefisien keragaman $(\mathrm{KK})$ data yang diperoleh.

\section{HASIL PENELITIAN}

Uji kualitatif dilakukan untuk mengetahui apakah bahan yang digunakan memiliki kualitas yang baik. Pada penelitian ini digunakan amilum ubi jalar sebagai bahan penghancur dalam pembuatan tablet. Uji kualitatif amilum ubi jalar meliputi uji organoleptis, pengamatan mikroskopik dan uji identifikasi. Hasil uji kualitatif amilum ubi jalar dapat dilihat pada tabel 2.

Tabel 2. Hasil uji kualitatif amilum ubi jalar.

\begin{tabular}{lll}
\hline No. & \multicolumn{1}{c}{ Jenis Uji } & \multicolumn{1}{c}{ Hasil } \\
\hline & Organoleptis & \\
a. Bentuk & a. Serbuk halus \\
b. Warna & b. Putih \\
c. Bau & c. Tidak berbau \\
d. Rasa & d. Tidak berasa \\
\hline 2. & Identifikasi dengan pereaksi lod & Positif berwarna biru. \\
\hline & Pengamatan Mikroskopik bentuk & $\begin{array}{l}\text { Amilum ubi jalar berbentuk bulat } \\
\text { sampai oval, dengan bentuk yang tidak } \\
\text { 3. }\end{array}$ \\
& Serbuk & \\
\hline
\end{tabular}

Keseragaman ukuran tablet persyaratan keseragaman ukuran dimaksudkan untuk menguji tablet yang tertera pada monografi. keseragaman ukuran tablet dari Hasil uji keseragaman ukuran dari masing-masing formula yang dibuat masing-masing formula, dapat dilihat kemudian dibandingkan dengan pada tabel 3. 
Formulasi tablet paracetamol secara kempa langsung dengan menggunakan variasi konsentrasi amilum ubi jalar (Ipomea batatas Lamk.) sebagai penghancur

Tabel 3. Hasil uji keseragaman ukuran tablet paracetamol dengan bahan penghancur amilum ubi jalar.

\begin{tabular}{cccccc}
\hline \multirow{2}{*}{ Formula } & \multicolumn{3}{c}{ Ulangan } & \multirow{2}{*}{ Jumlah } & \multirow{2}{*}{ Rata-Rata } \\
\cline { 2 - 4 } & $\mathbf{1}$ & $\mathbf{2}$ & $\mathbf{3}$ & & \\
\hline F I & 2,93 & 2,92 & 2,91 & 8,76 & 2,92 \\
F II & 2,91 & 2,92 & 2,91 & 8,74 & 2,91 \\
F III & 2,92 & 2,94 & 2,92 & 8,78 & 2,92 \\
\hline Jumlah $(\mathrm{mm})$ & 8,76 & 8,78 & 8,74 & 26,28 & 8,75 \\
\hline
\end{tabular}

Keseragaman bobot

dimaksudkan untuk menguji

keseragaman bobot tablet dari

masing-masing formula yang dibuat

kemudian dibandingkan dengan persyaratan keseragaman bobot yang tertera dalam monografi. Hasil uji keseragaman bobot dari masingmasing formula dapat dilihat pada tabel 4.

Tabel 4. Hasil uji keseragaman bobot tablet paracetamol dengan bahan penghancur amilum ubi jalar.

\begin{tabular}{cccccc}
\hline \multirow{2}{*}{ Formula } & \multicolumn{3}{c}{ Ulangan } & \multirow{2}{*}{ Jumlah } & \multirow{2}{*}{ Rata-Rata } \\
\cline { 2 - 4 } & $\mathbf{1}$ & $\mathbf{2}$ & $\mathbf{3}$ & & \\
\hline F I & 598,32 & 598,25 & 597,87 & 1794,44 & 598,14 \\
F II & 597,47 & 597,96 & 596,92 & 1792,35 & 597,45 \\
F III & 598,14 & 596,99 & 598,16 & 1793,29 & 597,76 \\
\hline Jumlah $(\mathrm{mg})$ & 1793,93 & 1793,2 & 1792,95 & 5380,08 & 1793,36 \\
\hline
\end{tabular}

Kerapuhan tablet dimaksudkan untuk menguji kerapuhan tablet dari masingmasing formula yang dibuat kemudian dibandingkan dengan persyaratan kerapuhan yang tertera dalam monografi. Hasil uji kerapuhan dari masing-masing formula dapat dilihat pada tabel 5.

Tabel 5. Hasil uji kerapuhan tablet paracetamol dengan bahan penghancur amilum ubi jalar.

\begin{tabular}{cccccc}
\hline \multirow{2}{*}{ Formula } & \multicolumn{3}{c}{ Ulangan } & \multirow{2}{*}{ Jumlah } & \multirow{2}{*}{ Rata-Rata } \\
\cline { 2 - 4 } & $\mathbf{1}$ & $\mathbf{2}$ & $\mathbf{3}$ & & 0,6 \\
F I & 0,19 & 0,22 & 0,19 & 0,6 & 0,19 \\
F II & 0,20 & 0,22 & 0,17 & 0,59 & 0,18 \\
F III & 0,19 & 0,19 & 0,17 & 0,55 & 0,57 \\
\hline
\end{tabular}

Kekerasan tablet dimaksudkan untuk menguji kekerasan tablet dari masing-masing formula yang dibuat kemudian dibandingkan dengan persyaratan kekerasan yang tertera dalam monografi. Hasil uji kekerasan 
Formulasi tablet paracetamol secara kempa langsung dengan menggunakan variasi konsentrasi amilum ubi jalar (Ipomea batatas Lamk.) sebagai penghancur

tablet dari masing-masing formula dapat dilihat pada tabel 6 .

Tabel 6. Hasil uji kekerasan tablet paracetamol dengan bahan penghancur amilum ubi jalar.

\begin{tabular}{|c|c|c|c|c|c|}
\hline \multirow{2}{*}{ Formula } & \multicolumn{3}{|c|}{ Ulangan } & \multirow{2}{*}{ Jumlah } & \multirow{2}{*}{ Rata-Rata } \\
\hline & 1 & 2 & 3 & & \\
\hline F I & 4,75 & 4,88 & 4,96 & 14,59 & 4,86 \\
\hline $\mathrm{F}$ II & 4,72 & 4,91 & 4,88 & 14,51 & 4,83 \\
\hline F III & 4,84 & 4,69 & 4,82 & 14,35 & 4,78 \\
\hline Jumlah (kg) & 14,31 & 14,48 & 14,66 & 43,45 & 14,47 \\
\hline
\end{tabular}

Penetapan kadar zat aktif terdisolusi. Hasil persen zat terdisolusi dilakukan dengan pangujian disolusi, tablet paracetamol dengan digunakan untuk mengukur penghancur amilum ubi jalar dapat availabilitas obat, terutama pada dilihat pada tabel 7 . penentuan zumlah zat aktif yang

Tabel 7. Hasil uji disolusi tablet paracetamol dengan bahan penghancur amilum ubi jalar

\begin{tabular}{cccc}
\hline \multirow{2}{*}{ Tablet } & \multicolumn{3}{c}{ Formula (\%) } \\
\cline { 2 - 4 } & $\mathbf{I}$ & $\mathbf{I I}$ & III \\
\hline 1 & 80,7466 & 110,1408 & 95,8525 \\
2 & 97,1429 & 89,9938 & 94,4815 \\
3 & 92,0062 & 98,1316 & 98,9541 \\
4 & 98,1869 & 104,5336 & 105,0191 \\
5 & 103,3488 & 91,9509 & 101,6835 \\
6 & 89,3447 & 83,5263 & 108,5510 \\
Jumlah & $\mathbf{5 6 0 , 7 7 6 1}$ & $\mathbf{5 7 8 , 2 7 7}$ & $\mathbf{6 0 4 , 5 4 1 7}$ \\
Rata-rata & $\mathbf{9 4 , 4 6 2 6}$ & $\mathbf{9 6 , 3 7 9 5}$ & $\mathbf{1 0 0 , 7 5 6 9}$ \\
\hline
\end{tabular}

Ket : Dalam waktu 30 menit harus larut tidak kurang dari $80 \%(\mathrm{Q}) \mathrm{C}_{8} \mathrm{H}_{9} \mathrm{NO}_{2}$, dari jumlah yang tertera pada etiket.

\section{PEMBAHASAN}

Berdasarkan hasil penelitian kompresi tablet paracetamol yang dilakukan dengan metode kempa langsung yang merupakan pembuatan tablet tanpa adanya adanya proses granulasi yang memerlukan eksipien yang cocok sehingga memungkinkan untuk dikempa secara langsung. Metode ini digunakan sebab memiliki keuntungan antara lain : tahapan produksinya sangat singkat (hanya pencampuran dan pengempaan), peralatan yang dibutuhkan tidak banyak, prosesnya lebih singkat, dapat digunakan untuk zat aktif yang tidak tahan panas dan tidak tahan lembab, waktu hancur dan disolusinya lebih baik karena tidak melewati proses 
Formulasi tablet paracetamol secara kempa langsung dengan menggunakan variasi konsentrasi amilum ubi jalar (Ipomea batatas Lamk.) sebagai penghancur

granul, tetapi langsung menjadi partikel.

Pemilihan bahan penghancur (amilum ubi jalar) dan bahan pengikat (avicel PH 102), dimana amilum ubi jalar mengandung amilosa $17,41 \%$ dan amilopektin 82,13\%. Pada konsentrasi $5 \%, 10 \%$ dan $15 \%$ amilum ubi jalar menghasilkan daya hancur tablet yang cukup baik, dimana fungsi bahan penghancur yaitu menarik air kedalam tablet, mengembang dan menyebabkan tablet pecah menjadi bagian-bagian, dan akan sangat menentukan kelarutan dari obat tersebut sehingga tercapainya bioavailabilitas yang diharapkan, untuk menghasilkan tablet yang kompak digunakan avicel PH 102 karena avicel memiliki sifat-sifat partikel yaitu ikatan hidrogen pada gugus hidrogen dalam molekul selulosa yang berdekatan hampir tersendiri dan bertanggung jawab untuk kekuatan dan kekohesifan padatan (kompak), dari sifat-sifat tersebut avicel $\mathrm{PH} 102$ dapat menghasilkan tablet paracetamol yang lebih kompak.

Hasil pengamatan dari uji organoleptis yang dilakukan pada serbuk amilum ubi jalar, yaitu menunjukkan bahwa amilum ubi jalar berupa serbuk halus, berwarna putih, tidak berbau dan tidak berasa. Pada uji identifikasi digunakan pereaksi iodium yang merupakan pereaksi umum yang digunakan untuk identifikasi karbohidrat, dari uji tersebut diperoleh hasil berupa warna biru tua yang menunjukkan bahwa serbuk yang diuji adalah benar serbuk amilum ubi jalar. Kemudian serbuk amilum ubi jalar tersebut dilihat bentuknya dengan menggunakan mikroskop, hasil menunjukkan bahwa amilum ubi jalar berbentuk bulat sampai oval, dengan bentuk yang tidak beraturan atau hampir bulat. Berdasarkan uji kualitatif yang dilakukan dapat dikatakan bahwa bahan penghancur yang digunakan adalah benar amilum ubi jalar.

Uji mutu fisik yang dilakukan terhadap tablet menurut Farmakope Indonesia sebagai buku standar resmi yaitu keseragaman bobot, keseragaman ukuran, kerapuhan dan kekerasan tablet. Pengujian tersebut bertujuan untuk mengetahui kualitas tablet dari masing-masing formula dalam kaitannya dengan persyaratan untuk tablet.

Uji keseragaman ukuran adalah uji untuk mengetahui diameter dan ketebalan tablet yang dihasilkan agar tablet memiliki ukuran yang sama atau agar ukuran tablet tidak berbeda. Hasil perhitungan pada uji 
Formulasi tablet paracetamol secara kempa langsung dengan menggunakan variasi konsentrasi amilum ubi jalar (Ipomea batatas Lamk.) sebagai penghancur

keseragaman ukuran tablet keretakan tablet selama pengemasan, paracetamol pada tabel 3, bahwa semua formula memenuhi persyaratan uji keseragaman ukuran seperti yang tertera dalam Farmakope Indonesia Edisi III yaitu diameter tablet tidak lebih dari 3 kali dan tidak kurang dari 1 $1 / 3$ kali tebal tablet.

Pada uji keseragaman bobot tablet pada tabel 4. menunjukkan semua formula memenuhi persyaratan Farmakope Indonesia Edisi III yaitu untuk tablet yang bobotnya lebih dari 300 mg, jika ditimbang satu persatu maka tidak lebih dari dua tablet yang masing-masing bobotnya menyimpang dari bobot rata-rata sebesar $5 \%$ dan tidak satu pun yang menyimpang dari bobot rata-rata sebesar $10 \% . U j i \%$ kerapuhan tablet pada tabel 5, memenuhi persyaratan Farmakope Indonesia yang menyatakan bahwa kehilangan berat lebih kecil dari 0,5\% sampai $1 \%$ masih dapat diterima.

Kekerasan tablet merupakan faktor yang penting dalam pengujian sifat fisik tablet untuk melihat pengaruh penggunaan bahan penghancur dalam formulasi tablet. Kekerasan tablet merupakan parameter yang menggambarkan kekuatan atau ketahanan tablet terhadap berbagai guncangan mekanik seperti goncangan, benturan dan terjadi penyimpanan, transportasi sampai ke tangan konsumen. Semakin besar tekanan yang diberikan pada waktu pentabletan, maka tablet yang dihasilkan akan semakin keras. Dari tabel 6, diperoleh hasil bahwa formula I, II, dan III memenuhi persyaratan Farmakope Indonesia, yaitu tidak satu tablet pun yang kekerasannya dibawah $4 \mathrm{~kg}$ dan tidak ada satu tablet pun yang kekerasannya lebih dari 8 kg. Faktor yang mempengaruhi kekerasan tablet antara lain sifat bahan yang dicetak, jumlah bahan penghancur, bahan pengikat dan kompresibilitas bahan.

Berdasarkan hasil perhitungan statistik dengan menggunakan analisis sidik ragam (uji F) terhadap uji keseragaman ukuran seperti pada lampiran $2 \mathrm{c}$, diperoleh nilai $\mathrm{F}_{\text {-hitung }}$ sebesar 1,67 dengan $\mathrm{F}_{\text {-tabel }}$ pada taraf $5 \%(0,05)=5,14$ nilai tersebut menunjukkan bahwa nilai $F$ hitung $<F$ tabel, sehingga perbedaan konsentrasi bahan penghancur amilum ubi jalar yang ditambahkan dalam formulasi tablet paracetamol berbeda tidak signifikan terhadap keseragaman ukuran tablet paracetamol, hal ini disebabkan oleh jarak antara punch dan die sudah tepat pada saat pengempaan. 
Formulasi tablet paracetamol secara kempa langsung dengan menggunakan variasi konsentrasi amilum ubi jalar (Ipomea batatas Lamk.) sebagai penghancur

Perhitungan uji $\mathrm{F}$ terhadap uji keseragaman bobot diperoleh nilai Fhitung sebesar 1,52 dengan $\mathrm{F}_{\text {-tabel }}$ pada taraf $5 \%(0,05)=5,14, F$ hitung $<F$ tabel, sehingga perbedaan konsentrasi bahan penghancur amilum ubi jalar yang ditambahkan dalam formulasi tablet paracetamol berbeda tidak signifikan terhadap keseragaman bobot tablet paracetamol, hal ini disebabkan oleh penimbangan dan pencampuran bahan hingga homogen sehingga keseragaman bobotnya memenuhi persyaratan.

Hasil perhitungan uji $\mathrm{F}$ terhadap uji kerapuhan diperoleh nilai $\mathrm{F}_{\text {-hitung }}$ sebesar 1,67 dengan $\mathrm{F}_{\text {-tabel }}$ pada taraf $5 \%(0,05)=5,14$, nilai tersebut menunjukkan bahwa nilai $\mathrm{F}$ hitung $<\mathrm{F}$ tabel, sehingga perbedaan konsentrasi bahan penghancur amilum ubi jalar yang ditambahkan dalam formulasi tablet paracetamol berbeda tidak signifikan terhadap kerapuhan tablet paracetamol, ini berarti penggunaan amilum ubi jalar pada konsentrasi $5 \%$ dapat memberikan kerapuhan yang relatif sama dengan penggunaan konsentrasi $10 \%$ dan $15 \%$, selain itu disebabkan oleh bahan penghancur yang telah divariasikan konsentrasinya dalam formula tablet telah kompak dengan bahan lainnya sehingga membentuk sediaan tablet kompresi yang baik.

Pada perhitungan uji $\mathrm{F}$ pada uji kekerasan tablet diperoleh nilai $F$ hitung sebesar 1,67 dengan $F$ tabel pada taraf $5 \%(0,05)=5,14$, artinya nilai $F$ hitung $<F$ tabel, sehingga dapat disimpulkan bahwa penambahan amilum ubi jalar dengan perbedaan konsentrasi menghasilkan kekerasan tablet yang tidak signifikan, ini berarti penggunaan amilum ubi jalar pada konsentrasi $5 \%$ dapat memberikan kekerasan yang relatif sama dengan penggunaan konsentrasi $10 \%$ dan 15 $\%$, selain itu disebabkan oleh bahan penghancur yang digunakan cukup kompak dengan bahan aktif dan bahan tambahan lainnya saat dikompresi menjadi suatu tablet.

Disolusi adalah proses dimana suatu senyawa aktif atau bentuk sediaan padat menjadi terlarut dalam media pelarut. Uji disolusi ketiga formula memenuhi persyaratan uji disolusi yang tertera di Farmakope Indonesia Edisi IV yaitu dalam waktu 30 menit harus larut tidak kurang dari $80 \%$ (Q) paracetamol dari jumlah yang tertera pada etiket. Hasil uji disolusi menggunakan 6 tablet, karena nilai $Q$ yang diperoleh lebih dari $80 \%$ sehingga memenuhi syarat pada tahap 
Formulasi tablet paracetamol secara kempa langsung dengan menggunakan variasi konsentrasi amilum ubi jalar (Ipomea batatas Lamk.) sebagai penghancur

$\mathrm{S}_{1}$. Dimana tahap $\mathrm{S}_{1}$, enam tablet diuji dan hasilnya dapat diterima.

\section{KESIMPULAN}

Metode yang digunakan pada penelitian ini adalah metode kempa langsung. Tablet paracetamol dengan bahan penghancur amilum ubi jalar pada uji disolusi dengan konsentrasi $5 \%, 10 \%$ dan $15 \%$, memenuhi syarat sebagai penghancur. Uji statistik menunjukkan bahwa penggunaan amilum ubi jalar dengan konsentrasi 5 $\%, 10 \%$ dan $15 \%$ berbeda tidak signifikan terhadap keseragaman ukuran, keseragaman bobot, \% kerapuhan dan kekerasan tablet.

\section{DAFTAR PUSTAKA}

1. Lachman L, Lieberman HA, Kanig, JL. Teori dan Praktek Farmasi Industri. Terjemahan Siti Suyatmi. Ed III. Jakarta : Universitas Indonesia Press, 1994.

2. Gennaro AR. Remington: The Science and Practice of Pharmacy $20^{\text {th }}$ Ed. Philadelphia : University of The Sicience in Philadelphia, 1990. 